\title{
AS LÓGICAS DOS PRODUTORES INVISÍVEIS: SIGNIFICADOS CULTURAIS NA PRODUÇÃO AGRÍCOLA FAMILIAR ${ }^{1}$
}

\author{
Marlon Dalmoro ${ }^{2}$ \\ Luciane Medeiros $^{3}$ \\ Jandir Pauli ${ }^{4}$ \\ Michael Vieira do Amarante ${ }^{5}$
}

http://dx.doi.org/10.1590/1413-2311.155.58137

\begin{abstract}
RESUMO
A produção agrícola tem adotado padrões mundiais, orientada por uma lógica produtivista por meio da produção em larga escala, busca constante de melhora de desempenho, aproveitamento da terra e maximização dos lucros. Estes significados orientam as atividades dentro da comunidade de produtores (PRESS; ARNOULD; MURRAY et al., 2014), mas demonstram-se distantes das lógicas da agricultura familiar, construídas a partir da valorização de aspectos sociais e culturais. Dessa forma, este estudo tem como objetivo compreender a criação de significados culturais acerca da agricultura familiar e a forma como estes significados resultam na construção de lógicas distintas aquelas predominantes no agronegócio. Com base num referencial teórico acerca da construção de significados culturais, adotou-se uma abordagem exploratória por meio de um conjunto de entrevistas com pequenos produtores rurais. Os resultados forneceram três categorias chaves que permeiam a criação de significados na agricultura familiar: formação identitária dos produtores, significados dos alimentos e relações sociais. A análise integrada dos resultados indica a construção de lógicas envolvendo aspectos identitários, sociais, culturais e de produção particulares da agricultura familiar. Os resultados contribuem com o desenvolvimento de políticas públicas e mercadológicas alternativas aquelas predominantes no agronegócio e que respeitam os significados culturais produzidos internamente em grupos não hegemônicos na representação social do universo agrícola.
\end{abstract}

Palavras-chave: Significados Culturais. Lógicas Culturais. Agronegócio. Agricultura Familiar. Pequenos Produtores.

\section{THE LOGIC OF THE INVISIBLE PRODUCERS: CULTURAL MEANINGS IN FAMILY FARMING}

\footnotetext{
${ }^{1}$ Recebido em 28/08/2015; aprovado em 26/05/2017.

${ }^{2}$ UNIVATES - marlon.dalmoro@univates.br.

${ }^{3}$ IMED - luciane_demedeiros@yahoo.com.br.

${ }^{4}$ IMED - jandir@imed.edu.br.

${ }^{5}$ IMED - michaelamarante @ yahoo.com.br.
} 


\begin{abstract}
Agriculture has adopt global patterns, oriented by a productivist logic involving large scale production, developing strategies for better performance and land exploration and profit maximization. These meanings orient practices inside the farms community (PRESS; ARNOULD; MURRAY et al., 2014), but misrepresent small farms reality, each are involved in alternative social and cultural logics. Thus, this study aims to understand the creation of cultural meanings about family farms and how these meanings result in the construction of different logics those prevailing in agribusiness. Based on a theoretical framework about the construction of cultural meanings, it adopted an exploratory approach through a series of interviews with small farmers. The results provided three key categories that permeate the creation of meaning in family farming: identity formation of producers meanings of food and social relations. The integrated analysis of the results shows the construction of logical involving identity, social, cultural and private production of family farming. The results contribute to the development of alternative public policies and market those prevailing in agribusiness and respecting the cultural meanings internally produced in non-hegemonic groups in social representation of agribusiness universe.
\end{abstract}

Keywords: Cultural Meanings. Cultural Logics. Agribusiness. Family Farming. Small Producers.

\title{
LA LÓGICA DE PRODUCTORES INVISIBLES: SIGNIFICADO CULTURAL EN LA FAMILIA DE PRODUCCIÓN AGRÍCOLA
}

\section{RESUMEN}

La producción agrícola ha adoptado estándares globales, guiados por una lógica productivista través de la producción a gran escala, en constante búsqueda de la mejora del rendimiento en el uso del suelo y la maximización de las ganancias. Estos significados orientan las actividades de la comunidad agrícola (PRENSA; ARNOULD; MURRAY et al., 2014), pero aparecen distintos en la lógica de la agricultura familiar, construida a partir de la apreciación de los aspectos sociales y culturales. Por lo tanto, este estudio tiene como objetivo comprender la creación de significados culturales acerca de la agricultura familiar y cómo estos significados resultan en la construcción de lógicas diferentes de las que prevalecen en la agroindustria. Desde un marco teórico acerca de la construcción de significados culturales, esta investigación tiene un enfoque exploratorio a través de una serie de entrevistas con pequeños agricultores. Los resultados proporcionaron tres categorías fundamentales para la creación de sentido en la agricultura familiar: formación de la identidad de los productores, significados de los alimentos y relaciones sociales. El análisis integrado de los resultados indica la construcción de lógicas basados en aspectos de identidad, sociales, culturales y de producción propios de la agricultura familiar. Los resultados contribuyen con el desarrollo de políticas públicas y de mercado alternativas frente las vigentes en la agroindustria, con respecto de los significados culturales producidos internamente en grupos no hegemónicos en la representación social de lo universo agrícola.

Palabras-clave: Significados Culturales; Lógica Cultural. Agroindustria. Agricultura familiar; Pequeños productores. 


\section{INTRODUÇÃO}

A produção agrícola mundial tem sido orientada por uma lógica referida como 'produtivista', a qual orienta comportamentos e atitudes dos produtores (BURTON, 2004). Esta lógica é definida como a prática de usar a terra no seu potencial máximo, criando e utilizando mecanismos que maximizem os resultados dos processos produtivos (EGOZ; BOWRING; PERKINS, 2001). A incorporação dessa lógica pelos produtores reforça um etos de 'bom fazendeiro' para aquele produtor que incrementa ao máximo sua produção, tornando a produtividade o principal elemento da cultura agrícola contemporânea (WILSON, 2001). Para Fitzgerald (2003), essa lógica leva a uma construção social que compreende uma propriedade rural como uma fábrica. O que por sua vez, está alinhada com lógicas contemporâneas de marketing, que buscam uma constante ampliação do desempenho empresarial a partir da adoção de determinada orientação estratégica (KOHLI; JAWORSKI, 1990).

A lógica produtivista acaba por construir uma rede de significados atrelados à produção agrícola como: maximização dos ganhos, avanços na utilização de produtos químicos, monocultura, desenvolvimento tecnológico e mecanização (WILSON, 2001; BURTON, 2004). Estes significados, por sua vez, são negociados e orientam as atividades dentro da comunidade de produtores, influenciando suas práticas e formação de identidade enquanto produtor (BURTON, 2004). Os produtores que incorporam esses significados constroem argumentos ideológicos como forma de legitimar as suas orientações estratégicas, tornando-se agentes ativos - os produtores visíveis do agronegócio - e reforçam a lógica produtivista (PRESS; ARNOULD; MURRAY et al., 2014).

Analisando o agronegócio globalizado, observa-se que os pequenos produtores que não possuem condições de atuar no mercado em virtude da sua produção em pequena escala, não encontram suporte na lógica produtivista do agronegócio para guiar suas práticas (FRIEDLAND, 2010). Este fato é explicado pela tensão entre a concepção de natureza associada à produção em pequena escala e ao controle e alteração do mundo natural buscado pela lógica produtivista (PRESS; ARNOULD, 2011; PRESS; ARNOULD; MURRAY et al., 2014).

No caso da produção agrícola brasileira, não é diferente. Enquanto a lógica predominante tem sido aquela produtivista ligada ao agronegócio, a agricultura familiar, associada a produção em pequena escala e a utilização de mão-de-obra exclusivamente familiar, busca encontrar lógicas alternativas para guiar suas práticas. Conforme o Ministério 
do Desenvolvimento Agrário (MDA), a agricultura familiar é responsável pela produção de 70\% alimentação da população brasileira (PORTAL PLANALTO, 2012). Contudo, apesar da relevância destes produtores, ao focar nas condições da agricultura familiar, entende-se que o universo no qual estes agricultores estão inseridos encontra-se numa posição díspar em relação ao agronegócio. Significados relacionados à família e a subsistência sobressaem nestas pequenas propriedades, e são distantes daqueles significados associados à lógica produtivista do agronegócio.

Tomando a agricultura familiar como contexto de estudo, observa-se que as práticas de produção na agricultura familiar não necessariamente possuem uma conexão com as lógicas prevalecentes no mercado agrícola. Reconhecendo que os significados estão localizados num mundo culturalmente constituído, a cultura seria transferida para as práticas por meio de rituais que buscam a manipulação dos significados (MCCRACKEN, 2003). Dessa forma, os produtores atuariam ativamente na transformação dos significados culturais na tentativa de estabelecer lógicas próprias para guiar as práticas no mundo em que vivem (DE CERTEAU, 1990). Conceituando cultura como uma teia de experiências, significados e ações (GEERTZ, 1983), entender as particularidades dos produtores ligados à agricultura familiar envolve compreender como estes indivíduos criam significados para o mundo em que vivem a partir dos bens (DOUGLAS; ISHERWOOD, 1978) que produzem.

Neste contexto, o presente estudo busca compreender a criação de significados culturais entre pequenos agricultores, e a forma como estes significados resultam na construção de lógicas distintas daquelas predominantes no agronegócio. Enquanto os significados de consumo têm sido amplamente debatidos na literatura (DOUGLAS; ISHERWOOD, 1978; MCCRACKEN, 2003), a construção de significados por parte dos produtores tem sido um tanto quanto negligenciada. No entanto, reconhecendo que as construções ideológicas determinam a orientação estratégica dos produtores de mercado (PRESS; ARNOULD; MURRAY et al.., 2014), analisar como estes constroem significados, permite ampliar a compreensão das configurações sociais e culturais que estão por detrás das relações de mercado. Isso decorre do fato de que estas relações se fazem entre atores sociais também por meio de trocas simbólicas (DOUGLAS; ISHERWOOD, 1978), e os bens produzidos servem como meios para estas trocas.

O contexto agrícola demonstra potencial para analisar este fenômeno, uma vez que está alinhado com os paradigmas atuais de desenvolvimento social, crescimento econômico e inovação tecnológica que permeiam as lógicas contemporâneas de produção e consumo (FITZGERALD, 2003). Além disso, a agricultura tem sido tomada como um importante 
contexto para a geração de conhecimento no âmbito das relações de mercado (WILKIE e MOORE, 2003) e do pensamento social brasileiro (TRAGTENBERG, 1982). Os resultados buscam reforçar a importância de considerar o produtor de mercado - especialmente aqueles produtores com pouca capacidade de agência - como construtores de significados atrelados aos bens e às práticas de produção e consumo em um determinado mercado. A evidenciar os significados que regem a produção agrícola familiar, espera-se contribuir com os esforços no desenvolvimento de políticas públicas e mercadológicas capazes de incluir grupos de produtores excluídos do modelo de produção hegemônico no agronegócio. Esta perspectiva é detalhada nas quatro partes que seguem esta introdução.

\section{REFERENCIAL TEÓRICO}

\subsection{AGRICULTURA FAMILIAR COMO MECANISMO DE PRODUÇÃO}

A expressão 'agricultura familiar' ganhou força nos últimos anos, especialmente depois da formalização do Programa Nacional de Fortalecimento da Agricultura Familiar Pronaf (BRASIL, 2015) e também pelo avanço das políticas voltadas a este setor com a criação do Ministério do Desenvolvimento Agrário (MDA). Some-se a isso a Lei ${ }^{\circ} 11.326$ de 24 de julho de 2006, que estabelece diretrizes para a formulação da Política Nacional da Agricultura Familiar e Empreendimentos Familiares Rurais, definindo uma série de critérios para determinar quais estabelecimentos rurais apresentam gestão familiar.

Essas ações de institucionalização da agricultura familiar no Brasil acompanharam um movimento internacional nos anos 1990, que buscou criar condições de produção alternativa à expansão da agricultura de larga escala e com capacidade recuperar a identidade social e cultural associada à vida do agricultor (BURTON, 2004). Este movimento é descrito por Press e Arnould (2011) como um elemento de contracultura. No caso brasileiro se vincula ao Movimento de Pequenos Agricultores e a posições políticas que debatem as tensões culturais criadas entre o agronegócio moderno e formas de produções artesanais, voltadas para a subsistência e sem o emprego de mão de obra assalariada. O suporte do Estado à produção em pequena escala visa preservar os papeis de ordem social da agricultura familiar, criando emprego e renda para agricultores excluídos das lógicas produtivistas do agronegócio (BITENCOURT e ABRAMOVAY, 2003; CAUME, 2009). Assim, na busca por descrever as relações sociais no espaço agrário brasileiro, o termo agricultura familiar substituiu termos 
como 'agricultura de baixa renda', 'agricultura de subsistência', entre outros (CAUME, 2009).

Dessa forma, a agricultura se torna, também, uma forma de identidade própria, distinta pelo fato de estar atrelada a um significado de vida, um senso de pertencimento a um grupo que se enxerga como produtor de alimentos. No entanto, a luta simbólica pela legitimação deste grupo de produtores passa, também, pela tentativa de obter visibilidade num ambiente dominado por grandes corporações ligadas ao agronegócio global (WANDERLEY, 2001).

Enquanto a agricultura familiar tem encontrado apoio para preservar as características da produção em pequena escala, a legitimação simbólica ainda carece de atenção em diferentes planos sociais. No entendimento de Caume (2009), a agricultura familiar necessita ser tratada em três planos interligados e dinâmicos, a partir de objetivos diferenciados: (a) categoria social relacionada aos processos de auto identificação dos indivíduos para que se sintam em igual posição e que apresentam as mesmas necessidades; (b) categoria sociológica que se refere à construção social legitimada pelo campo do conhecimento, pela ciência; e (c) objeto de política pública no qual a agricultura familiar é definida como operacional e sua qualificação é oferecida pela necessidade do aparelho de Estado prover um recorte seletivo dos potenciais beneficiários da política. A agricultura familiar é, além de um objeto político, uma forma social de produção que se afirma para que a família detenha o controle da produção e realize as atividades produtivas. Além disso, para Abramovay (1992), a agricultura familiar possui três traços básicos: (a) os membros estão relacionados por parentesco ou casamento; (b) a propriedade dos negócios é usualmente combinada com controle gerencial; e (c) o controle é transmitido de uma geração para outra dentro da mesma família.

Deste modo, a agricultura familiar é um segmento que possui relações baseadas em laços de parentesco e laços afetivos de vizinhança, formando um arranjo social particular enquanto forma de produção. Para Caume (2009), as relações sociais se intensificam no momento em que os produtores prestam auxílios uns aos outros sem qualquer envolvimento financeiro, apenas troca de serviços e ajuda mútua. Em complemento, considera que mesmo que haja contratações temporárias e limitadas, a instabilidade econômica da agricultura familiar exige que a renda obtida se torne uma estratégia de reprodução da família e da unidade produtora.

A organização da produção em torno de um arranjo social próprio e que permeia a vida social dos produtores marca a noção de propriedade e pertencimento ao território. A propriedade rural passa a ser o local de intermediação dos seus costumes, valores, saberes, 
crenças. Os aspectos simbólicos do cotidiano dos produtores rurais se dogmatizam e sacralizam por meio de práticas e hábitos que se reproduzem de geração em geração, construindo as identidades destes produtores. Desta forma, a produção agrícola em pequena escala consiste num movimento de territorialização da produção e distribuição de alimentos, reforçando significados estabilizados, mas distintos daqueles reproduzidos pela produção em larga escala e reproduzidos pelos fluxos culturais de modernidade global (THOMPSON; COSKUNER-BALLI, 2007). Dessa forma, entende-se que a agricultura familiar segue lógicas próprias, construídas a partir de significados oriundos de crenças, práticas tradicionais, valores morais e éticos, simbologias e sentimentos de identificação e pertencimento particulares.

\subsection{O PAPEL DOS SIGNIFICADOS NA PRODUÇÃO AGRÍCOLA}

Para McCracken (2003), em virtude da atenção que os aspectos culturais exigem na compreensão das práticas de produção e consumo, a busca por novas compreensões dos sistemas simbólicos consiste numa demanda constante para compreender os comportamentos concretos dos agentes de mercado. O próprio MacCraken, já em 1986, reforçava a importância dos aspectos simbólicos, argumentando que a cultura é a lente pela qual o indivíduo enxerga os fenômenos, além de servir como base da atividade humana. Assim, o autor destaca que a cultura constitui o mundo, suprindo-o de significados. Para isso, a construção de significados ocorre à luz das categorias e princípios culturais, ou seja, distinções básicas dos fenômenos e ideias e valores que orientam a lógica específica que uma determinada cultura avalia e interpreta estes fenômenos.

Nesta mesma linha, Douglas e Isherwood (1978) também destacaram a relação entre significados e relações sociais. Para os autores, os códigos traduzem as relações sociais e permitem classificar coisas, pessoas e produtos. Esse entendimento está alinhado com Sahlins (1979), que evidencia o código cultural como o elemento que governa a utilidade prática das coisas. Para o autor, a produção não passa de um precipitado de uma racionalidade. Assim, na sociedade ocidental as lógicas econômicas passariam a ser o lócus privilegiado de produção simbólica. Os objetos e bens estariam, assim, inseridos no universo dos sistemas simbólicos culturalmente constituídos. A produção de bens deixa, então, de ser uma mera prática lógica de eficiência material e reflete de a intenção cultural dos produtores (SAHLINS, 1979).

Dessa forma, os bens, e a sua produção primária, podem ser um recurso para elaborar esquemas categóricos de uma cultura, dando forma a diferentes categorias culturais por meio 
da discriminação visual (MACCRAKEN, 1986). Por isso, a produção de objetos pode ser vista como um ritual que contribui com a oferta e reforço de símbolos culturais e relações sociais, não de forma autônoma, mas reflexo de uma ordem social construídas nas práticas cotidianas (DOUGLAS; ISHERWOOD, 1978; MACCRAKEN, 1986). Com isso, os bens passam a ter a capacidade de atuar como indicador de posição social e pertencimento a grupos sociais, não só pelo consumo, mas também nas suas lógicas de produção (CANCLINI, 2001).

Apesar dos significados culturais - na perspectiva de Douglas e Isherwood (1978) e de MacCraken (186) - terem sido tomados como uma das principais lentes para a compreensão do consumidor, deve-se reconhecer que os significados culturais permeiam as relações sociais como um todo, envolvendo também o produtor. Dessa forma, a compreensão dos significados atrelados aos bens deve ir além das suas formas de consumo, visto que estes estão atrelados a relações dinâmicas de produção, circulação e consumo (FREDERICO, 2008; PINTO; LARA 2011). Assim, na articulação teórica deste estudo, evoca-se a necessidade de ler as reflexões acerca de significados e bens para além do consumo, enfatizando também os aspectos de produção que lhe complementa. Conforme a concepção clássica proposta por Marx (1988), a produção é mediadora do consumo e sem ela, este não teria objeto.

Uma vez que os significados culturais são atribuídos aos bens e consistem numa forma de pertencimento a um grupo (DOUGLAS; ISHERWOOD, 1978; MACCRAKEN, 1986), o desafio é justamente compreender como os significados culturais formam as lógicas que orientam as ações de produção. Para isso, evoca-se a concepção de Baudrillard (1968), para quem o mercado é uma ideologia e não apenas uma realidade. O autor utiliza a noção de lógica para retratar as diferentes faces da produção, do consumo e do próprio mercado. A lógica de produção compreendida pelo autor parte da concepção de valor/signo, na qual a realidade social é representada por códigos que passam a dominar a produção e o consumo social, estruturando a realidade. Com isso, a forma de produção e organização dominaria a constituição da realidade, não por meio de modos de produção, mas por códigos de produção.

Para Hall (2003), o caráter habitual e universal dos códigos em uso produzem reconhecimentos aparentemente naturais, tornando a operação social por meio de determinados códigos naturais. Ou seja, significados podem ser distribuídos em uma cultura ou comunidade, influenciando as práticas dos indivíduos nela inseridos de forma a serem considerados como algo dado naturalmente e que, aparentemente, não foi construído externamente. Essa perspectiva é especialmente relevante na compreensão dos significados culturais relacionados com a produção agrícola. Como comentado na Introdução, a lógica produtivista se constrói em cima de significados naturalizados entre os produtores rurais. 
As ações sociais, por sua vez, reforçam e são orientadas por estas lógicas, uma vez que os significados culturais são utilizados para codificar, organizar e regular a conduta dos indivíduos. Os significados dão sentido às ações práticas e, tomados em conjunto, constituem uma cultura. Por isso, mesmo que uma pessoa não seja perfeitamente representada por um conjunto de significados, ela se sentirá atraída por um como forma de encontrar 'um lugar para sí', uma fonte de identificação. Isso sugere que os significados não emergem de um centro interior, mas de um diálogo entre conceitos e definições criadas socialmente pelos discursos de uma cultura, passando a ser incorporados na busca de uma fonte de identificação (HALL, 1997).

Na produção agrícola, as lógicas culturais trazidas pela industrialização esvaziaram o simbolismo da vida simples do campo, fazendo deste tipo de produção uma forma de acumulação mediada por mecanismos de mercado, em detrimento de um modo de vida (PRESS; ARNOULD, 2011). A construção de significado passa, assim, por transformações muitas vezes conflitantes entre o valor prático do contato com a natureza e aquele mundo urbano e globalizado associado às lógicas de mercado em um complexo e diverso sistema global regulado por grandes empresas que padronizam os sistemas de produção (FRIEDMANN, 1993).

Importante para esse estudo é reconhecer que este processo envolve o estabelecimento de significados tidos como verdadeiros acerca dos bens produzidos, que passam a ser utilizados nas relações sociais tanto pelos agricultores, quanto pela sociedade em geral (LIEPINS, 2000). Estudos prévios em grupos de produtores rurais que buscam estabelecer modos de produção alternativos demonstram que os significados culturais compartilhados por estes produtores tendem a ser incorporados pelo mercado, por meio de estratégias de cooptação (THOMPSON; BALLI, 2007). Assim, os significados culturais assumem um papel relevante na orientação das práticas de produção agrícola, reforçando a importância de compreender os diferentes aspectos simbólicos e lógicas culturais envolvidos na construção do mercado de alimentos, especialmente de mercados alternativos que não operam sob a lógica produtivista.

\section{MÉTODO}

Para compreender os significados e lógicas culturais atrelados a produção de alimentos na agricultura familiar, lança-se mão de um olhar interpretativo por meio de um estudo qualitativo. Esta orientação metodológica demonstrou-se adequada, pois reconhece nos dados 
subjetivos a possibilidade de enfatizar experiências pessoais em relação a eventos, processos e estruturas que traduzem os significados culturais (DENZIN; LINCOLN, 2006). A compreensão dos significados se concretiza por meio de uma relação intersubjetiva entre o pesquisador, os dados coletados e os entrevistados. Consistindo assim numa construção social a partir de experiências subjetivas dos indivíduos (BURREL; MORGAN, 1979).

A condução do estudo partiu da premissa de que os entrevistados não estão expressando estritamente o seu ponto de vista, mas sim articulando um sistema de significados culturais selecionado do seu contexto cultural e criativamente adaptado para atender seus objetivos particulares (THOMPSON, 1997). Assim, alinhado com a virada cultural que reconfigura os elementos presentes nas análises sociais, a cultura assume uma posição substantiva para compreender tanto os indivíduos participantes da pesquisa quanto o sistema social que estes vivem.

O foco no contexto da agricultura familiar ocorreu devido a suas características diferenciadas. De modo geral, os produtos comercializados ou produzidos para subsistência das famílias possuem características peculiares e, com isso, a rede de significados consiste numa organização que envolve tanto bens quanto aspectos culturais envoltos nas praticas cotidianas. Especificamente, o estudo foi realizado na região norte do estado do Rio Grande do Sul. Nesta região, a produção agrícola possui grande representação econômica, social e política, fazendo parte do cotidiano das pessoas. No entanto, as pequenas propriedades rurais dividem espaço com grandes fazendas produtoras de grãos, como trigo e soja; contrastando a tecnologia empregada nestas propriedades com o modo de vida campesino das propriedades que possuem agricultura familiar. Com isso, a rede de significados é amplificada para além da propriedade rural, permeando o modo de vida da população e contrastando lógicas produtivistas com lógicas ligadas a agricultura campesina.

A coleta de dados envolveu entrevistas em profundidade com 10 agricultores familiares, habitantes da região norte do Rio Grande do Sul. Para a condução das entrevistas, foi elaborado um roteiro com perguntas abertas, abordando como aspectos principais o histórico dos produtores na atividade, os significados culturais acerca do alimento e da agricultura familiar e as relações sociais dos produtores. Apesar da utilização do roteiro, a condução das entrevistas buscou capturar as respostas subjetivas de cada entrevistado, sem se atrelar restritamente ao roteiro e seguindo o fluxo da conversa. Todas as entrevistas foram transcritas e organizadas por entrevistado, para dar suporte à análise dos dados. O Quadro 1 identifica cada um dos participantes do estudo e a estrutura das propriedades rurais. 
Quadro 1- Identificação dos entrevistados

\begin{tabular}{|c|c|c|c|}
\hline Nome & Idade & Principais Cultivos & Estrutura Familiar \\
\hline Ivonilde & 61 anos & Hortifruti, ovos, queijo. & Casada, 7 filhos - 1 solteiro mora na propriedade \\
\hline Jussara & 32 anos & $\begin{array}{l}\text { Soja, milho, hortifruti, } \\
\text { galinhas, suínos, feijão. }\end{array}$ & $\begin{array}{l}\text { Solteira, sem filhos. Pai, mãe e } 5 \text { irmãos, sendo que } \\
1 \text { casada e com filhos. Pai e cunhado comandam o } \\
\text { negócio, mas todos trabalham na propriedade. }\end{array}$ \\
\hline $\begin{array}{l}\text { Maria e } \\
\text { Renato }\end{array}$ & $\begin{array}{l}59 \text { e } 63 \\
\text { anos }\end{array}$ & $\begin{array}{l}\text { Leite, queijo, suínos, galinhas, } \\
\text { feijão, milho e mandioca. }\end{array}$ & Casal, 2 filhos - nenhum na propriedade. \\
\hline Valdírio & 64 anos & Soja, milho, cevada, leite. & $\begin{array}{l}\text { Casado, } 2 \text { filhos. A mulher e uma filha moram na } \\
\text { propriedade e ajudam, mas trabalham fora. }\end{array}$ \\
\hline Marlise & 59 anos & $\begin{array}{l}\text { Leite, hortifruti, pequena } \\
\text { agroindústria de pães, } \\
\text { bolachas e cucas. }\end{array}$ & $\begin{array}{l}\text { Casada, } 4 \text { filhos }-2 \text { moram na propriedade e } \\
\text { ajudam, mas trabalham fora. }\end{array}$ \\
\hline Cláudia & 34 anos & $\begin{array}{l}\text { Soja, milho, trigo, leite, } \\
\text { pastagem. }\end{array}$ & $\begin{array}{l}\text { Casada, tem duas filhas pequenas. Ela e o marido } \\
\text { trabalham na propriedade. }\end{array}$ \\
\hline Marisa & 49 anos & $\begin{array}{l}\text { Soja, trigo, leite, pastagem, } \\
\text { hortifruti, artesanato. }\end{array}$ & $\begin{array}{l}\text { Casada, } 3 \text { filhos - fazem faculdade, moram na } \\
\text { propriedade e ajudam quando podem. }\end{array}$ \\
\hline Jocemar & 28 anos & $\begin{array}{l}\text { Soja, milho, trigo, cevada, } \\
\text { hortifruti. }\end{array}$ & $\begin{array}{l}\text { Solteiro. Trabalha no cultivo de hortifrúti com a } \\
\text { mão. Pai trabalha com grãos. }\end{array}$ \\
\hline Fátima & 53 anos & Gado, leite, suínos. & Casada, 2 filhos fora da propriedade. \\
\hline Osmar & 64 anos & $\begin{array}{l}\text { Suínos, galinhas, mandioca, } \\
\text { feijão, gado para consumo. }\end{array}$ & Casado, 3 filhos fora da propriedade. \\
\hline
\end{tabular}

Fonte: elaborado pelos autores.

Para as análises, os dados foram categorizados seguindo as orientações de Lofland e Lofland (1995), envolvendo a identificação de códigos e categorias. A partir da organização das falas dos entrevistados, foi possível observar a eminência de um conjunto de códigos. Estes códigos foram agrupados em uma segunda releitura, visando tornar a sua descrição densa sem perder a dimensão dos significados inerentes a eles. Dessa forma, emergiram três categorias capazes de abarcar todos os códigos observados na interpretação dos dados: história de vida (formação identitária) dos produtores; significados acerca dos alimentos e da agricultura familiar; e relações sociais dos agricultores. Após a organização dos dados em categorias, os resultados foram reanalisados na busca de conexões abstratas entre as falas, visando identificar conexões lógicas na forma como os entrevistados constroem significados para interpretarem o seu mundo. Foram identificadas quatro lógicas distintas: cultural, familiar, social e de produção, apresentadas na parte final deste artigo.

\section{ANÁLISE DOS RESULTADOS}

A descrição e análise dos significados culturais acerca da agricultura familiar foram elaboradas a partir da concepção teórica adotada neste estudo, considerando os simbolismos imbuídos nas falas dos entrevistados quando estes relatam sua relação com a agricultura familiar e o modo de vida. Como foi mencionado acima, as entrevistas evidenciaram três 
categorias que permeiam a construção de significados acerca da agricultura familiar. A primeira diz respeito à relação dos entrevistados com a agricultura familiar, denominada de 'formação identitária dos produtores'. A segunda trata dos significados relacionados ao produto das suas ações, ou seja, o alimento, categorizada como 'significado dos alimentos'. A terceira categoria evidencia a importância das relações sociais no compartilhamento dos significados, denominada assim de 'relações sociais na agricultura familiar'. Cada uma dessas categorias é detalhada a seguir.

\subsection{FORMAÇÃO IDENTITÁRIA DOS PRODUTORES}

Como já abordado no referencial teórico, uma das características da agricultura familiar é que os produtores mantêm de modo arraigado a noção de propriedade e de pertencimento ao território na sua formação identitária. Este fato ficou evidente durante as entrevistas, quando os produtores destacaram que o vínculo deles com a agricultura foi passado de geração em geração, como na fala da entrevistada Marlise: "essa propriedade é herança do meu pai. Desde que nós casamos, nós trabalhamos aqui. Tivemos quatro filhos nesta propriedade [...] ainda tem dois que moram aqui e nos ajudam".

Assim, a herança da propriedade reforça um sentimento de pertencimento, visto que naquele local os antepassados viveram, construíram suas vidas, e, em seguida, os próprios entrevistados também construíram suas vidas naquele local e proveram o sustento de seus filhos. Além disso, a herança proporcionou também a continuidade das atividades exercidas pelos pais ou ainda, de antepassados mais longínquos: "a propriedade já era herança dos meus avós. Os meus pais morreram e cada um de nós ficou com um pedacinho. Uns venderam e a gente vai tocando os negócios junto" (Maria e Renato).

A propriedade assume dessa forma um sentido de vida e de trabalho, deixando suas vidas restritas àquele local, o que reforça o sentido de pertencimento. Esse sentimento é repassado para os filhos, projetando uma expectativa de que os filhos deem continuidade na produção rural. Inclusive, alguns entrevistados relatam que começam a introduzir a ideia de sucessão familiar na propriedade quando os filhos ainda são pequenos, como por exemplo, a entrevistada Cláudia, que tem duas filhas e demonstra o desejo de que elas fiquem na propriedade no futuro:

A mais velha vai ser um pouco mais difícil, mas a pequena eu estou conseguindo incentivar. Ela gosta muito de estar no meio dos 
animais, das vacas. Quando chega a tardinha e eu pego um par de luvas, ela já diz: mãe, tirar leite! Isso é uma das nossas preocupações, a sucessão familiar. Por isso a gente está tentando incentivar a pequena a ver que o que a gente faz aqui não é um fardo, é bom.

Observa-se uma preocupação com o fato dos filhos e netos não desejarem dar continuidade ao histórico familiar como produtor rural, haja vista as dificuldades da vida no campo. Para isso, esperam incentivos do governo que tornem viável a manutenção da propriedade agrícola.

Aqui a gente faz o negócio da gente e sobrevive. E de repente um dos filhos fica para dar continuidade. Eles até tem interesse e ajudam como podem. Acho que precisaria mais incentivos pra agricultura familiar. Pelo meu ponto de vista, porque se a agricultura vai mal, a cidade também não sobrevive mais. (Marlise)

Na propriedade é família, um filho cuida do abatedor, o marido cuida os porcos, minha nora cuida as vacas e eu venho atender na feira. Tenho três netos homens e gostaria que eles dessem continuidade pra não vir pra cidade tirar emprego dos outros, entrar em drogas de repente. Eles têm dez, quatro e três anos e já incentivo. Estou ajudando a segurar as pontas para eles não virem pra cidade. Gostaria demais que eles ficassem no interior. (Fátima)

O argumento central para a preservação da propriedade é que a agricultura é vital para a sociedade como um todo. Como destacado na fala da entrevistada Marlise, a cidade depende do campo e assim criar um mecanismo para a permanência do jovem no campo é vital. Além disso, a mesma entrevistada comenta que sua vida é inteiramente significada a partir da vida no campo, e a vida na cidade seria um desafio: "nós vamos sair daqui e morar na cidade só no dia que não conseguir trabalhar mais. Por que na cidade vou fazer o que? Tenho até a quinta série, vou procurar emprego no que?’. O entrevistado Jocemar, por sua vez, relata que até buscou morar na cidade, mas que não deu certo, mencionando que: "eu gosto daqui das atividades que eu tenho aqui". 
A relação entre o campo e a cidade aparece, assim, como um elemento que ameaça a continuidade da propriedade familiar e, consequentemente, o sentimento de pertencimento. $\mathrm{Na}$ análise do histórico familiar, a herança familiar determinou a trajetória de vida e de trabalho dos entrevistados. Dessa forma, a agricultura familiar dá significado à vida, sendo a terra o elemento balizador da história de vida dos entrevistados. Visando dar continuidade a essa trajetória, a noção de propriedade é transmitida de pai para filhos. A expectativa de que a família permaneça conectada pro meio da propriedade, faz emergir uma expectativa de que os filhos deem continuidade à produção rural.

Em adição, ao conversar sobre o papel do histórico familiar na formação da identidade como agricultor com os entrevistados, aspectos da tradição familiar conflitam com as lógicas produtivistas disseminadas no agronegócio. Alguns entrevistados enfatizam o conhecimento passado de pai para filho e os aspectos da sabedoria popular, reforçando um conjunto de significados próprios, ligados à preservação das práticas de produção tradicionais.

A gente tem que saber o tempo de plantar, o tempo de colher. Que nem a mandioca, nós plantamos na (lua) minguante que aí você cozinha o ano inteiro e não é amarga. A gente vai muito atrás da lua pra plantar as coisas. Quem ensinou isso foram os antigos, os pais e os avôs. Diz que o milho se a gente planta na (lua) nova ele caruncha, então a gente não planta nessa lua, tem que ser na crescente, cheia. Isso quem ensina é a vida, os antepassados ensinaram as coisas. (Maria e Renato)

Por outro lado, o desejo de ampliar a produção, adotando técnicas contemporâneas que alterem as formas tradicionais de produção é transmitido aos produtores por meio de cursos oferecidos por associações ou empresas do setor do agronegócio. Os entrevistados que participam destes cursos destacam a necessidade de informação, alinhando suas falas com a reprodução de significados produtivistas a partir do desenvolvimento tecnológico:

A gente precisa ter as informações, fazer os cursos técnicos que disponibilizam. Eu estou sempre me atualizando, precisa porque se não você fica pra trás. Eu estou participando do grupo da administração e do gado leiteiro também [...] tu sempre fica sabendo alguma coisa diferente, o que é novidade né. (Marlise) 
Assim, na análise da formação identitária dos produtores, observa-se que enquanto alguns entrevistados evocam a tradição como um elemento basilar na construção dos significados para as suas práticas de produção, outros incorporam aspectos ligados à modernização, como o desenvolvimento tecnológico. As influências externas, recebidas nos cursos de qualificação, auxiliam na construção de significados alinhados com a ideia de 'bom fazendeiro', reproduzindo, mesmo dentro de pequenas propriedades uma cultura agrícola contemporânea, voltada para o desenvolvimento tecnológico (WILSON, 2001).

\subsection{SIGNIFICADOS DOS ALIMENTOS}

A segunda categoria tratada neste estudo envolve a construção de significados acerca dos alimentos. Este item se complementa ao significado de pertencimento observado na categoria anterior, reforçando o alimento como representando tudo na vida dos entrevistados. Esta interpretação é balizada por frases como: "o significado do alimento pra mim é a vida" (Cláudia); e reforçada para associação entre alimento e a palavra 'tudo': “ $O$ alimento é tudo né. A saúde começa pela boca. Se tu não tiver uma boa alimentação, tu vai adoecer. E a boa alimentação começa pela feira, porque a gente traz tudo produto fresquinho. A gente carneia ontem e hoje traz tudo novinho. As pessoas não levam nada pra casa congelado ou estragado" (Fátima).

A conexão entre alimento e vida é reforçada por uma preocupação no fornecimento de alimentos para a população de forma geral, fazendo também um contraponto aos alimentos industrializados. Para os entrevistados, o alimento produzido por eles é puro, ou seja, sem a adição (ou com reduzida adição) de agrotóxico ou resultado de produção em larga escala: “Aqui é diferente. Se nós colher o feijão, o milho, é tudo sem veneno, sem nada. É puro. O leite é puríssimo, não tem soda, não tem ureia, não tem nada, nem uma misturinha. Os porcos são engordados só com lavagem, ai até a banha é mais saudável que o azeite comum" (Maria e Renato).

A percepção de pureza é contraposta com o perigo de comprar alimentos prontos, como exemplificados na fala do entrevistado Jocemar: "o alimento produzido na propriedade tem mais qualidade do que você pegar fora, a gente nunca sabe o que está trazendo de fora." Como destacado por Douglas (2010), a pureza é uma ideia relativa que se constrói a partir do perigo em que se incorre, ou seja, faz parte de uma unidade funcional que busca manter uma ordem social. A significação de alimento como 'tudo' e 'puro' se contrapõem ao urbano e ao industrializado e altera o sistema de classificação do homem do campo. Para isso, aquilo que é 
produzido na propriedade é significado como puro, natural, em contraponto ao alimento industrializado, conectado a produção em larga escala com uso intensivo de agrotóxicos. Esse sentimento está conectado com o que Thompson e Balli (2007) descrevem como percepção sistêmica de risco da agricultura industrial.

Outro aspecto observado nesta categoria diz respeito à significação dos alimentos como uma forma de subsistência. Das propriedades dos entrevistados, todas têm o autoconsumo como uma das suas características básicas. Segundo Grisa (2007), o tamanho das propriedades rurais pode ser fator limitante para a subsistência das famílias, tornando um fator explicativo na diferenciação entre formas contemporâneas de produção em larga escala e agricultura familiar. Assim, o autoconsumo não está atrelado à improdutividade ou desqualificação do produtor, mas a um papel assumido e a significados diferenciados que estes constroem em torno da sua visão de agricultura. A fala da entrevistada Cláudia expressa essa percepção; para ela, o sustento está em primeiro plano e a comercialização da produção é uma consequência que acaba garantido o sustento de outros: "O alimento é o sustento. Significa muito para nós. Além de trazer o nosso sustento do dia a dia, ainda a gente vende e vai saber quantas pessoas se beneficiam disso".

Os entrevistados que comercializam seus produtos em feiras locais, como associações ou cooperativas e, até mesmo, para o varejo diretamente, mostram uma preocupação com a subsistência de terceiros a partir da comercialização de alimentos. A produção agrícola é tomada como um elemento fundamental para a subsistência, ao invés de benefícios financeiros: "O alimento a gente tem que ver da melhor forma e tratar bem para ser saudável, não pode ser uma ferramenta para ganhar dinheiro" (Jocemar).

Assim, somente o excedente é comercializado, visto que o alimento produzido deve primeiramente garantir a subsistência da família. Como a entrevistada Ivonilde explica, eles produzem alimentos "pro gasto, pro consumo", e revendem para vizinhos produtos como leite e ovos, visto que sua produção é superior ao consumo pela família. Ao assumir um papel fundamental para a sobrevivência, o alimento passa a ter significados sagrados que se distanciam da esfera profana da comercialização (BELK; WALLENDORF; SHERRY, 1989).

Além disso, a significação da produção como forma de subsistência e não como um negócio é reforçada pela percepção de falta de competitividade frente à produção em larga escala: "Eu acho que a gente não consegue competir no mercado porque a gente planta só para sobreviver mesmo, muita pouca coisa o pai vende" (Jussara). No entanto, os produtores criam uma dinâmica de mercado distinta daquelas ligadas ao agronegócio (produção e comercialização em larga escala), evocando feiras e trocas com vizinhos como um mecanismo 
de distribuição e que permite exaltar a produção de alimentos como um modo de vida, ao invés de um negócio. Com isso, mesmo se considerando pequenos, se sentem importantes dentro do sistema agrícola nacional como um todo, pois sustentam as suas famílias e ajudam no sustento de outras famílias com o fornecimento de alimentos 'puros'. Esse fato ajuda a dar sentido às suas vidas, imbuindo nos alimentos não só um significado de subsistência, mas também um todo, um modo de vida.

\subsection{RELAÇÕES SOCIAIS}

De forma complementar aos significados construídos em torno dos aspectos históricos e dos alimentos, as relações sociais também consistem numa fonte de construção de significados na produção agrícola (BURTON, 2004; PRESS; ARNOULD; MURRAY et al., 2014). O primeiro aspecto que emerge nas análises é a família como núcleo social primário. Como a própria classificação social destes agricultores remete - agricultura familiar -, os entrevistados destacam que a família possui um "papel importante" (repetido por diversos entrevistados), compartilhando tarefas, ajudando nas práticas diárias. Além disso, a família torna-se o núcleo de convivência diária, uma vez que todas as atividades na propriedade costumam ser compartilhadas com todos os integrantes da família.

Um segundo aspecto diz respeito a associações ou cooperativas como núcleo social. Todos os entrevistados alegaram participar de algum tipo de associação, como igreja e associações comunitárias: "A gente participa das festas da comunidade e da igreja evangélica [...] acho isso muito importante" (Marlise). As cooperativas também foram destacadas por alguns produtores como mecanismo importantes no auxílio à produção e comercialização dos produtos: "Somos associados a cooperativas de crédito principalmente. Eles ajudam bastante" (Jocemar). Os entrevistados destacam também importância das cooperativas e associações quando precisam se relacionar com o mercado, uma vez que todos os produtores entrevistados possuem baixo nível de escolaridade e se julgam com poucas condições para negociar a compra de insumo ou mesmo encontrar meios para comercialização de seus produtos.

Ao envolver produtores que compartilham de significados culturais semelhantes, as associações ou cooperativas tornam-se locais saturadas de atitudes e valores que produzem sentido aos agricultores. Dessa forma, estes ambientes congregam pessoas semelhantes e permitem compartilhar valores que, de certa forma, empoderam os produtores por estarem unidos. Seguindo o pensamento de Hall (2003), os significados culturais são distribuídos 
dentro do grupo social, constituindo uma linguagem universal que torna natural as operações realizadas pelos produtores dentro do seu grupo social. A partir dos dados coletados, pode-se dizer que os agricultores familiares encontram na associação comunitária um espaço para compartilhar suas ideias e procuram unir-se em prol disso, auxiliando na construção de lógicas próprias. Essa constatação está alinhada com a cultura atribuída a modos de produção pastoril, que reforça valores agrários e comunitários nas práticas sociais (THOMPSON; BALLI, 2007).

Importante destacar que os laços sociais estão conectados com a história de vida dos entrevistados, conectando aspectos familiares, religiosos, comunitários e cooperativistas. Como na fala de uma entrevistada que menciona o fato de participar de cursos na cooperativa para encontrar os amigos: "No curso do gado leiteiro eu nem precisava porque é meu marido que tira o leite, mas achei importante por causa da amizade" (Cláudia). Assim, os significados construídos pelos entrevistados ligados à agricultura familiar encontram nos grupos sociais com os quais estes convivem, uma estrutura que permite a reprodução de significados comuns no seu grupo social. Essas estruturas permitem a expressão de valores, técnicas e práticas (PRESS; ARNOULD, 2011) e auxiliam na construção de lógicas próprias, distintas daquelas ligadas ao agronegócio.

\section{CONSIDERAÇÕES FINAIS}

Abordando o contexto da agricultura familiar, o plano empírico deste estudo buscou primeiramente compreender a criação de significados culturais entre pequenos agricultores. Para isso, observaram-se três categorias chaves na construção de significados, sendo elas: o histórico como produtor rural; os significados atribuídos aos alimentos; e as relações sociais em que os produtores estão envolvidos. Com base nestes resultados, buscaram-se conexões abstratas para identificar lógicas distintas à lógica produtivista predominante no agronegócio (WILSON, 2001; FITZGERALD, 2003; BURTON, 2004). Dessa forma, as redes de significados apresentadas no item anterior foram tomadas como suporte para a identificação de lógicas emergentes que envolvem os pequenos produtores rurais.

A primeira lógica está conectada com aspectos identitários. A produção agrícola familiar está diretamente ligada a um sentimento de pertencimento, resultado de uma construção histórica, de uma história de vida que começa com a herança da propriedade rural. Assim, conexão com a terra e desejo de continuidade na produção agrícola estão vinculados a uma percepção identitária de produtor rural. Essa lógica evoca aspectos identitários como uma 
razão para superar dificuldades da vida no campo e como um contraponto em relação ao modo de vida urbano.

A segunda lógica é cultural e envolve a construção de significados para o mundo em torno do alimento. O alimento assume significados de 'tudo', de vida, e sua produção, dentro da propriedade rural, garante um estado de pureza frente ao perigo da produção em larga escala e industrializada. Esta lógica é reforçada externamente pelo crescimento de um discurso que favorece modos de produção orgânico e locais e formas de comercialização alternativas, como feiras de produtores (FRIEDLAND, 2010). Esses discursos subsidiam os agricultores com argumentos para balizar suas decisões de produção distante da lógica produtivista do agronegócio.

Os aspectos sociais balizam a terceira lógica, envolvendo a família como um núcleo social fundamental para a manutenção da atividade agrícola. Este fato é reforçado pela característica da agricultura familiar que, na sua essência, não utiliza mão de obra assalariada. Além disso, os laços comunitários fortes são expressos pela participação em associações e cooperativas. A associação comunitária é significada como uma necessidade para lidar com a complexidade do mercado. Além disso, ela fornece um local de relacionamento, preservando uma posição social construída ao longo da vida e compartilhada entre os produtores. Os aspectos sociais foram identificados em outros estudos em comunidades de agricultores, reforçando o fato da cooperação como uma forma de galvanizar uma ideia de sobrevivência em um mundo dominado por lógicas distintas (THOMPSON; BALLI, 2007; PRESS; ARNOULD, 2011).

A quarta lógica envolve os aspectos anteriores na formação da concepção de produção própria. A lógica de produção predominante é aquela de subsistência e autoconsumo, ao invés da produção em larga escala e comercialização. Na agricultura familiar a comercialização é consequência da produção, visto que a prática agrícola está conectada com um significado de vida e não de negócio. A adoção de uma lógica de produção distinta também é vista como uma necessidade, dado a falta de competitividade da pequena propriedade rural e a adoção de canais de comercialização alternativos. O resultado, são modos de produção que valorizam a multicultura - ao invés da monocultura reproduzida pelo agronegócio (WILSON, 2001). No entanto, mesmo adotando modos de produção distintos, alguns produtores reproduzem a necessidade de desenvolvimento tecnológico reproduzido pelo discurso do agronegócio, em superação a formas tradicionais de produção.

Estas lógicas específicas reforçam a existência de significados particulares da agricultura familiar que não são incorporados nos significados atribuídos ao agronegócio 
contemporâneo. Esta reflexão está alinha com aquela encontrada por Press, Arnould, Murray et al. (2014) no estudo sobre produtores de trigo orgânico nos Estados Unidos. Naquele contexto, enquanto os grandes produtores de fertilizantes defendem uma agricultura dita científica e extensionista para proporcionar maiores ganhos, os pequenos produtores ligados à agricultura orgânica desejam preservar lógicas distintas. Ao destacar as lógicas particulares do contexto da agricultura familiar, contribui-se com o estudo de Press, Arnould, Murray et al. (2014) demonstrando que lógicas identitárias, culturais, sociais e de produção influenciam e são influenciadas por significados construídos a partir das condições de vida dos pequenos produtores, que os colocam numa situação distinta daquela compartilhada pelo agronegócio de forma geral. Enquanto as pequenas propriedades constituem o contexto dos agricultores que cultivam aquela terra e nela fazem suas histórias de vida, o agronegócio é visto como um vasto universo de grandes máquinas, avançada tecnologia e altos valores monetários em circulação (EGOZ; BOWRING; PERKINS, 2001; BURTON, 2004). Essa distinção simbólica torna os produtores da agricultura familiar invisíveis dentro das lógicas dominantes do agronegócio. Apesar de possuírem representação no volume total de alimento produzido, não representam as logicas dominantes do mercado.

De posse destes resultados, indica-se que a construção de políticas públicas e estímulo a práticas de mercado dos pequenos produtores rurais devem reconhecer as lógicas singulares que orientam a agricultura familiar. Significados estes que não estão conectados com lógicas de produção em larga escala (produtivista), mas por aspectos sociais, culturais, identitários e de produção para subsistência. Com isso, não se pode esperar que estes produtores ambicionem interagir dentro de uma lógica de tradicional, estrategicamente orientada ao mercado (KOHLI; JAWORSKI, 1990), mas que busquem alinhar suas práticas com significados que legitimam seu modo de vida.

Estes resultados trazem implicações para o marketing, destacando que nem todos os produtores operam ou desejam operar dentro das lógicas hegemônicas do mercado. $\mathrm{O}$ marketing pode se constituir em um aparato importante para articular lógicas políticas e econômicas distintas (BÖHM; BREI, 2008), caso se disponha a servir como ferramenta para solidificar formatos de produção mais humanos e socialmente alinhados, respeitando os significados produzidos internamente nos diferentes grupos sociais. A agricultura familiar é um exemplo disso, enfatizando a relação com a cultura dos pequenos agricultores, numa tentativa de preservar o modo de viver do pequeno agricultor e suas estratégias de reprodução social, mesmo diante das profundas transformações do agronegócio. A organização de um espaço social que reproduz as lógicas dos pequenos produtores retroalimenta formas de 
consumo alinhadas com essas lógicas, como, por exemplo, a alimentação orgânica ou em feiras livres. Em adição, o desenvolvimento de políticas públicas para este grupo social não pode partir de concepções produtivistas, nas quais as propriedades rurais sejam enquadradas como empreendimentos e os produtores ajam como empresários do campo, e sim reconhecer que a agricultura familiar é antes de tudo um modo de vida. Para isso, devem apoiar a construção de círculos sociais que reforcem a identificação e pertencimento do produtor ao grupo social, estabilizando um núcleo social familiar, criando condições de manutenção dos jovens, e valorizando a multicultura na produção de alimentos ao invés da monocultura e canais alternativos de comercialização.

Dessa forma, a compreensão das lógicas e dos significados do ponto de vista do produtor demonstrou ser um campo de estudo válido para compreender os conflitos de mercado, permitindo reconhecer principalmente distinções na construção dos significados hegemônicos e aqueles compartilhados por grupos invisíveis, ou seja, com pouco poder no estabelecimento das orientações de mercado. Futuros estudos podem buscar a construção de lógicas distintas, bem como confrontar em um mesmo plano empírico as lógicas dos grandes produtores com as dos pequenos produtores, evidenciando diferentes grupos sociais que possuem papel primordial no fornecimento de alimentos.

\section{REFERÊNCIAS}

ABRAMOVAY, R. Paradigmas do capitalismo agrário em questão. São Paulo: HUCITEC/Unicamp, 1992.

BAUDRILLARD, J. O Sistema dos objetos. São Paulo: Perspectiva, 1968.

BELK, R; WALLENDORF, M; SHERRY, J. The sacred and the profane in consumer behavior: theodicy on the Odyssey. Journal of Consumer Research, Chicago, v. 16, n. 1, p.1-38, 1989.

BITENCOURT, G. A.; ABRAMOVAY, R. Inovações institucionais no financiamento à agricultura familiar: o Sistema Cresol. Revista de Economia Ensaios, v. 16, n. 1, p. 179-208, 2003.

BÖHM, S.; BREI, V. Marketing the hegemony of development: of pulp fictions and green deserts. Marketing Theory, v. 8, n. 4, p. 339-366, 2008.

BRASIL. Programa nacional de fortalecimento da agricultura familiar - Pronaf.

Disponível em: http://www.mda.gov.br/sitemda/secretaria/saf-creditorural/sobre-o-programa. Acesso em: 22 abr. 2015. 
BURREL, G.; MORGAN, Ga. Sociological paradigms and organizational analysis.

London: Heinemann Educational, 1979.

BURTON, R. Seeing through the 'good farmer's'eyes: towards developing an understanding of the social symbolic value of 'productivist' behaviour. Sociologia Ruralis, v. 44, n. 2, p. 195-215, 2004.

CANCLINI, N. G. Consumidores e cidadãos: conflitos multiculturais da globalização. Rio de Janeiro: Editora da UFRJ, 2001.

CAUME, D.J. Agricultura familiar e agronegócio: falsas antinomias. REDES, v. 14, n. 1, p. 26-44, 2009.

DE CERTEAU, M. A invenção do cotidiano. Petrópolis: Vozes, 1990.

DENZIN, N.; LINCOLN, Y. O Planejamento da pesquisa qualitativa: teorias e abordagens. Porto Alegre: Artmed, 2006.

DOUGLAS, Mary; ISHERWOOD, Baron. The world of goods: towards and anthropology of consumption. New York: W.W. Norton, 1978.

DOUGLAS, Mary. Pureza e perigo. São Paulo: Editora Perspectiva, 2010.

EGOZ, S.; BOWRING, J.; PERKINS, H. Tastes in tension: form, function, and meaning in New Zealand's farmed landscapes. Landscape and Urban Planning, v. 57, n. 3, p. 177-196, 2001.

FITZGERALD, D. Every farm a factory: the industrial ideal in American agriculture. New Haven: Yale University Press, 2003.

FREDERICO, C. O consumo nas visões de Marx. In: BACCEGA, Maria A. (Org.).

Comunicação e culturas do consumo. São Paulo: Editora Atlas, 2008. p. 78-87.

FRIEDLAND, W. New ways of working and organization: alternative agrifood movements and agrifood researchers. Rural Sociology, v. 75, n. 4, p. 601-627, 2010.

FRIEDMANN, H. The political economy of food. New Left Review, v. 197, s.n., p. 29-5, 1993.

GEERTZ, C. Local knowledge. New York: Basic Books, 1983.

GRISA, C. A produção "pro gasto": um estudo comparativo do autoconsumo no Rio Grande do Sul. 2007. 201 f. Dissertação (Mestrado em Desenvolvimento Rural) Departamento de Ciências Econômicas, Universidade Federal do Rio Grande do Sul, Porto Alegre, RS, Brasil, 2007.

HALL, S. Representation: cultural representations and signifying practices. London: Sage, 1997.

HALL, S. Da Diáspora: identidades e mediações culturais. Belo Horizonte: Editora da 
UFMG, 2003.

KOHLI, A. K.; JAWORSKI, B. Market-orientation: the construct research propositions, and managerial implications. Journal of Marketing, v. 54, n. 2, p. 01-18, 1990. LIEPINS, R. Making men: the construction and representation of agriculture-based masculinities in Australia and New Zealand. Rural Sociology, v. 65, n. 4, p. 605-620, 2000. LOFLAND, J.; LOFLAND, L. Analyzing Social Settings: a guide to qualitative observation and analysis. Belmont, CA: Wadsworth Publishing Company, 1995.

MACCRAKEN, G. Culture and consumption: a theoretical account of the structure and movement of the cultural meaning of consumer goods. Journal of Consumer Research, $v$. 13, n. 1, p.71-84, 1986.

MACCRAKEN, G.. Cultura \& Consumo. Rio de Janeiro: Mauad, 2003.

MARX, K.. O Capital: crítica da economia política. Rio de Janeiro: Civilização Brasileira, 1988.

PINTO, M.R.; LARA, J. E. As experiências de consumo na perspectiva da teoria da cultura do consumo: identificando possíveis interlocuções e propondo uma agenda de pesquisa.

Cadernos EBAPE.Br, Rio de Janeiro, v. 9, n. 1, p. 37-56, 2011.

PORTAL PLANALTO. Agricultura familiar já produz 70\% dos alimentos consumidos no mercado interno do país. Disponível em: http://www.brasil.gov.br/economia-eemprego/2015/07/agricultura-familiar-produz-70-dos-alimentos-consumidos-por-brasileiro. Acesso em: 20 abr. 2015.

PRESS, M.; ARNOULD, E. Legitimating community supported agriculture through American pastoralist ideology. Journal of Consumer Culture, v. 11, n. 2, p.168-194, 2011. PRESS, M.; ARNOULD, E.; MURRAY, Je.B.; STRAND, K. Ideological challenges to changing strategic orientation in commodity agriculture. Journal of Marketing, v. 78, n. 6, p. 103-119, 2014.

SAHLINS, M. Cultura e razão prática. Rio de Janeiro: Zahar, 1979.

THOMPSON, C. J.; BALLI, G. C. Enchanting ethical consumerism: the case of community supported agriculture. Journal of Consumer Culture, v. 7, n. 3, p. 275-30, 2007. THOMPSON, C. J.; COSKUNER-BALLI, G. Countervailing market responses to corporate co-optation and the ideological recruitment of consumption communities. Journal of Consumer Research, v. 34, n. 2, p.135-52, 2007.

THOMPSON, C. Interpreting consumers: a hermeneutical framework for deriving marketing insights from the texts of consumers' consumption stories. Journal of Marketing Research, v. 34, n. 4, p. 438-455, 1997. 
TRAGTENBERG, M. Administración participativa en Brasil: Lages y Boa Esperança.

Revista Interamericana de Planificación, v. 63/64, s.n., p. 245-258, 1982.

WANDERLEY, N. Raízes históricas do campesinato brasileiro. In: TEDESCO, J. C. (Org.). Agricultura familiar: realidades e perspectivas. Passo Fundo: UPF, 2001. p. 21-55.

WILKIE, W. L.; MOORE, E. S. Scholarly research in marketing: Exploring the "4 eras" of thought development. Journal of Public Policy and Marketing, v. 22, n. 2, p. 116-146, 2003.

WILSON, G. From productivism to post-productivism... and back again? Exploring the (un)changed natural and mental landscapes of European agriculture. Transactions of the Institute of British Geographers, v. 26, n. 1, p. 77-102, 2001. 